\title{
ERRATUM
}

Ken-ichiro Inoue $\cdot$ Hirohisa Takano $\cdot$ Rie Yanagisawa

Takamichi Ichinose $\cdot$ Akinori Shimada

Toshikazu Yoshikawa

\section{Pulmonary exposure to diesel exhaust particles induce airway inflammation and cytokine expression in NC/Nga mice}

Received: 7 November 2005/Published online: 9 December 2005

(C) Springer-Verlag 2005

\section{Arch Toxicol (2005). DOI: 10.1007/s00204-005-0669-2}

There have been printing errors in Tables 2 and 3 of the paper. These are corrected as follows:

Table 2 Protein levels of cytokines and chemokines in BAL supernatants after challenge with DEP

\begin{tabular}{|c|c|c|c|c|c|}
\hline Group & $n$ & IL-4 & IL-5 & $\mathrm{KC}$ & MIP-1 $1 \alpha$ \\
\hline $\begin{array}{l}\text { Vehicle } \\
\text { DEP }\end{array}$ & $\begin{array}{l}18 \\
18\end{array}$ & $\begin{array}{l}66.3 \pm 11.0 \\
146.7 \pm 14.0^{*}\end{array}$ & $\begin{array}{l}4.93 \pm 1.73 \\
14.55 \pm 8.75\end{array}$ & $\begin{array}{l}62.8 \pm 10.2 \\
449.3 \pm 47.4^{* *}\end{array}$ & $\begin{array}{l}22.4 \pm 11.3 \\
161.4 \pm 9.6^{\text {** }}\end{array}$ \\
\hline
\end{tabular}

All values are in $\mathrm{pg} /$ total BAL supernatants. Results are mean $\pm \mathrm{SEM}$ $n$ number of animals

BAL fluid from mice were obtained 24 hours after the last administration of vehicle or DEP. Interleukin (IL)-4, IL-5, keratinocyte chemoattractant (KC), and macrophage inflammatory protein (MIP)-1 $\alpha$ levels in the BAL supernatants were measured by enzyme-linked immunosorbent assays

${ }^{*} P<0.05$ versus vehicle group, ${ }^{* *} P<0.01$ versus vehicle group

Table 3 Protein levels of cytokines and chemokines in the lung tissue supernatants after challenge with DEP

\begin{tabular}{llllll}
\hline Group & $n$ & IL-4 & IL-5 & KC & MIP-1 $\alpha$ \\
\hline Vehicle & 18 & $193.2 \pm 13.1 *$ & $1.64 \pm 1.10$ & $59.2 \pm 18.7$ & $17.9 \pm 8.1$ \\
DEP & 18 & $238.3 \pm 17.0^{*}$ & $0.53 \pm 0.53$ & $241.0 \pm 36.5^{*}$ & $145.9 \pm 31.7^{*}$ \\
\hline
\end{tabular}

All values are in $\mathrm{pg} /$ total BAL supernatants. Results are mean $\pm \mathrm{SEM}$ $n$ number of animals

Lungs from mice were obtained $24 \mathrm{~h}$ after the last administration of vehicle or DEP. IL-4, IL-5, KC, and MIP-1 $\alpha$ levels in the lung tissue supernatants were measured by enzyme-linked immunosorbent assays

$* P<0.01$ versus vehicle group

The online version of the original article can be found at http:// dx.doi.org/10.1007/s00204-005-0669-2

K. Inoue $\cdot H$. Takano $(\bowtie) \cdot R$. Yanagisawa

Inhalation Toxicology and Pathophysiology Research Team,

National Institute for Environmental Studies,

16-2 Onogawa, 305-8506 Tsukuba, Japan

E-mail: htakano@nies.go.jp

Tel.: + 81-298-502334

Fax: $+81-298-502334$

T. Yoshikawa $\cdot$ H. Takano

Inflammation and Immunology,

Graduate School of Medical Science,

Kyoto Prefectural University of Medicine, Kyoto, Japan

T. Ichinose

Department of Health Science,

Oita University of Nursing and Health Science,

Oita, Japan

A. Shimada

Department of Veterinary Pathology, Faculty of Agriculture,

Tottori University, Tottori, Japan 